\title{
El sistema
}
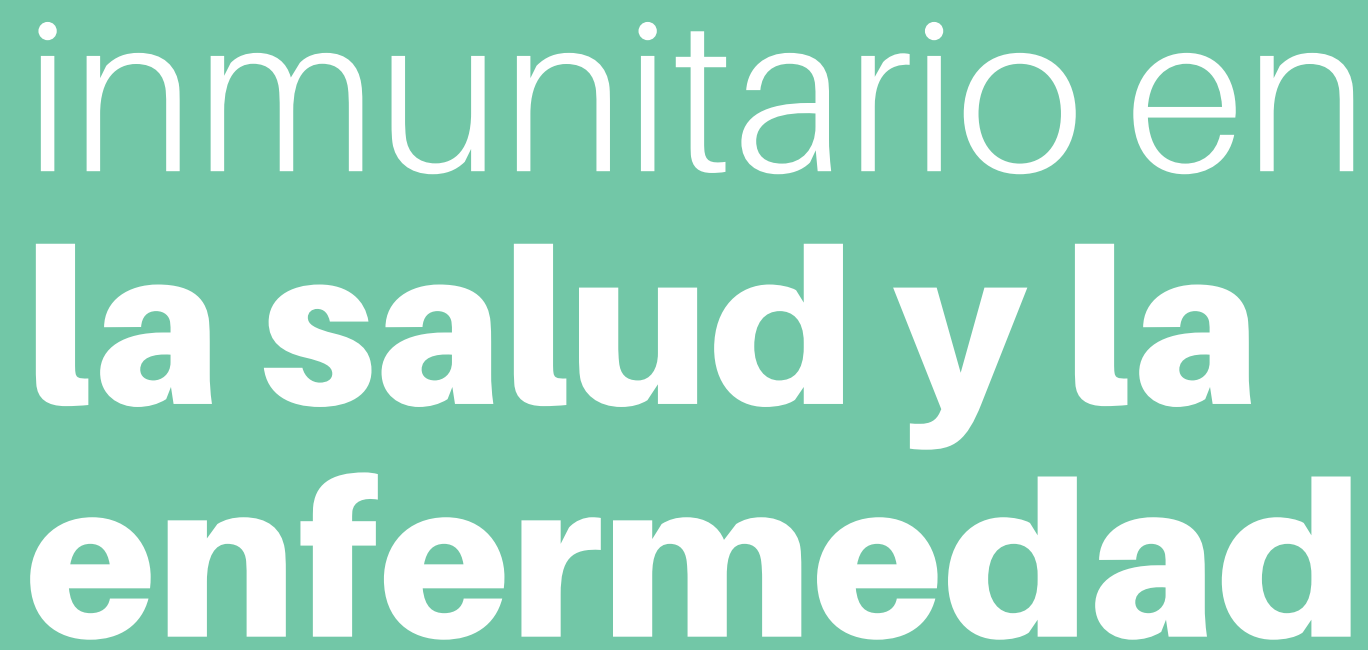

Rosa Andrea Zárate-Ramos, ${ }^{1}$ Sorely Adelina Sosa-Luis ${ }^{1}$ y William de Jesús Ríos-Ríos ${ }^{2}$ 


\section{Resumen}

El sistema inmunitario es ampliamente conocido por su relevancia para la protección del cuerpo contra agentes infecciosos. Sin embargo, cuando se sobreactivan (hipersensibilidad), cuando fallan (inmunodeficiencias) o cuando desconocen tejidos propios (autoinmunidad), estos mismos mecanismos de protección del sistema inmunitario pueden causar daños al organismo. Por lo anterior, este artículo aborda el funcionamiento del sistema inmunitario bajo los estados de salud y enfermedad, y cómo estos conocimientos han permitido su aplicación para diagnosticar, prevenir y tratar muchas enfermedades, resaltando una de sus principales contribuciones al desarrollo de la medicina actual: las vacunas.

Palabras clave: Tolerancia inmunitaria, linfocitos autorreactivos, autoinmunidad, alergias, inmunodeficiencias, vacunas.

\section{Abstract}

The immune system is widely known due to its relevance to the body's protection against infectious agents. Nevertheless, these same mechanisms of protection may damage the own tissues, when they are overactivated (hypersensitivity), when they fail (immunodeficiencies) or when they do not recognize their own tissues (autoimmunity). Therefore, this paper addresses how the immune system works in the presence of sickness or health, as well as how this knowledge has been applied to the diagnosis, prevention, and treatment of many diseases, highlighting one of its main contributions to the evolution of the current medicine: the vaccines.

Keywords: Immune tolerance, autoreactive lymphocytes, autoimmunity, allergy, immunodeficiencies, vaccines. 


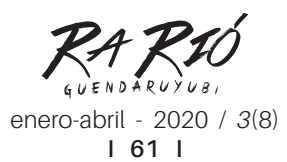

Por muchos años, los científicos se han dedicado a descifrar cómo el sistema inmunológico -conformado por una increíble red de mecanismos- es capaz de reaccionar contra agentes invasores mientras permanece tolerante a las moléculas del propio organismo. En circunstancias normales, erradicar una infección debe resultar en un equilibrio entre la eliminación directa del patógeno y la menor inducción de daño posible a tejidos propios.

En un mundo tan hostil, nos encontramos expuestos a muchos agentes que desencadenan enfermedades infecciosas, pero gracias a la observación del comportamiento de nuestro cuerpo ante ellas y a la experimentación con modelos animales y cultivos celulares, actualmente tenemos un amplio conocimiento de cómo funciona el sistema inmunitario. Esta información ha permitido grandes avances a la medicina, uno de los más relevantes y seguro son las vacunas, las cuales, desde su creación por Edward Jenner, en el siglo XVIII, han salvado millones de vidas (Abbas, Lichtman \& Pillai, 2018; Murphy, Travers \& Walport, 2009; Doherty \& Robertson, 2004).

\section{El sistema inmunitario en la salud y la enfermedad Tolerancia inmunológica}

El sistema inmunitario es capaz de coordinar al mismo tiempo la defensa frente a agresiones derivadas de microorganismos, células malignas y sustancias tóxicas, con la inducción del mínimo daño colateral para tejidos propios del cuerpo. A esto se le conoce como tolerancia inmunológica (Schwartz, 2012).

En primer lugar, los microorganismos comensales coexisten en simbiosis ${ }^{*}$ en muchas partes de nuestro cuerpo sin afectarnos, por ello son tolerados por la respuesta inmune innata (RII). Pero si una persona llega a estar inmunosuprimida*, algún microbio comensal puede 
comportase como oportunista para tratar de invadir al cuerpo; entonces la respuesta inmunitaria debe activarse como para cualquier patógeno (Zhao \& Elson, 2018).

Por otra parte, muchos de los linfocitos T (LT) y linfocitos B (LB) que se producen en la médula ósea son autorreactivos, esto significa que poseen receptores que pueden reconocer tejidos propios. Es por lo que los LT y los LB requieren seleccionarse en el timo y en la médula ósea, respectivamente, y que algunos LT autorreactivos sean seleccionados para diferenciarse a LT reguladores naturales, cuya función es colaborar para que el sistema inmunitario regrese a la homeostasis. Debido a que estos procesos evitan que desde su origen existan linfocitos autorreactivos, se les denomina tolerancia central (Figura 1) (Bluestone, 2011).

Adicionalmente, algunos de los LT vírgenes que se encuentran en los ganglios linfáticos pueden llegar a reconocer péptidos derivados de células propias "viejas" o de microorganismos comensales que son presentados por células dendríticas tolerogénicas. Estos LT se convierten en anérgicos* o en LT reguladores inducidos, que también evitarán la activación de la respuesta inmune. Debido a que lo anterior ocurre fuera de donde se producen los LT, se le llama tolerancia periférica (Figura 1) (Bluestone, 2011). En su conjunto, la tolerancia central y periférica evitan la existencia de linfocitos autorreactivos.

Cuando una mujer está embarazada, ¿por qué no rechaza inmunológicamente al feto si éste también expresa antígenos derivados de su padre?

En el útero existen factores que durante el embarazo inducen un ambiente tolerogénico. Uno de ellos lo proporciona la acción de hormonas femeninas, como los estrógenos, que favorecen la producción de células dendríticas tolerogénicas, aumentando la presencia de LT reguladores. La progesterona inhibe la activación de los LT y LB, elevando su apoptosis. Las células muertas por este proceso son eliminadas homeostáticamente por los macrófagos sin causar 


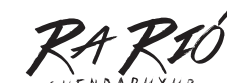

Hay varias enfermedadesen las que el sistema

inmunitario lleca a reconocer erróneamente

a células del oropio cueroo como si fueran

agentes invasores v las ataca

inflamación, lo que protege al embrión de un ataque inmunológico por parte del sistema inmunitario de la madre (Aluvihare, Kallilourdis \& Betz, 2004).

\section{Autoinmunidad: la traición del sistema inmunitario (autodestrucción)}

Hay varias enfermedades en las que el sistema inmunitario llega a reconocer erróneamente a células del propio cuerpo como si fueran agentes invasores y las ataca, provocando una autodestrucción. Dependiendo de los tejidos que afectan, se clasifican en enfermedades autoinmunes sistémicas o locales; un ejemplo de estas enfermedades en que la autodestrucción está localizada en un solo órgano es la diabetes mellitus tipo 1, cuyo órgano blanco es el páncreas. Algunas enfermedades autoinmunes sistémicas son la esclerodermia, que afecta la piel y otros órganos como el corazón, pulmones y riñones; así como la esclerosis múltiple, que daña al sistema nervioso central. Actualmente se han descrito más de cien enfermedades autoinmunes con afección en uno o más órganos del cuerpo (Jadue \& González, 2012).

Se ha investigado que las enfermedades autoinmunes se presentan más frecuentemente en mujeres que en hombres, y que existen factores de predisposición genética. Es decir, si alguna persona la padece, es más probable que alguno de sus descendientes la herede también. Asimismo, se han descrito alteraciones en los mecanismos de tolerancia central o periférica que permiten la existencia de LT autorreactivos, impidiendo una adecuada producción de LT reguladores con la consecuente formación de anticuerpos que reconocen células propias (autoanticuerpos) y, por lo tanto, las destruyen utilizando sus mecanismos efectores (Bosch, 2011). El descontrol del sistema inmunitario en estas enfermedades tiende a ser persistente y progresivo, pudiendo terminar en la muerte de quien las padece; así, la persona requiere recibir tratamiento durante toda su vida con medicamentos inmunosupresores que, como consecuencia, la predisponen a infecciones recurrentes (Figura 2). 


\section{Alergias (respondiendo exageradamente a un enemigo que no existe)}

Las enfermedades alérgicas son reacciones adversas del sistema inmunitario contra sustancias inofensivas, denominadas alérgenos (por ejemplo, polen, polvo, esporas de los hongos, ácaros, pelo de animales y algunas medicinas o alimentos como las nueces, mariscos, fresas, etcétera). Aunque todos los seres humanos estamos continuamente expuestos a una amplia gama de alérgenos, no todos desarrollamos alergias. En la mayoría, estas sustancias pasan desapercibidas; pero en algunas personas con predisposición genética, la exposición de al menos dos veces al mismo alérgeno provoca la activación exacerbada del sistema inmune (hipersensibilidad) (Calzada, Baos, Cremades \& Cárdaba, 2018; Scheurer, Toda \& Vieths, 2015). El primer contacto con el alérgeno produce una respuesta similar a la generada en contra de los parásitos, induciendo la producción de anticuerpos de tipo lgE. Debido a que los basófilos y mastocitos poseen receptores para la fracción constante de los anticuerpos lgE, estos anticuerpos se les pegan y a partir de ese momento dichas células quedan "sensibilizadas". Si la persona vuelve a tener uno o más contactos con su alérgeno, en cada exposición el alérgeno se unirá a las fracciones hipervariables de los anticuerpos IgE que se encuentran sobre los basófilos y mastocitos, provocando su degranulación y la liberación de histamina, entre muchos otros componentes (Figura 3). La histamina es la molécula principal inductora de las alergias, ya que su liberación es interpretada por el sistema inmunitario como una señal de daño que produce el incremento del flujo de la sangre y el tamaño de los vasos sanguíneos, con el consecuente aumento de líquidos en ese sitio, manifestándose como inflamación.

Una reacción alérgica puede ser local, tan ligera como unas simples ronchas en alguna parte del cuerpo, incluyendo lagrimeo, escurrimiento nasal y asma, hasta una reacción sistémica que puede provocar la pérdida de función en los pulmones y otros órganos del cuerpo, desembocando en la muerte de quien tuvo contacto con su alérgeno. Por lo anterior, una persona que se sabe alérgica a alguna sustancia debe evitar su contacto y prevenirse portando algún medicamento antihistamínico para tomarlo 


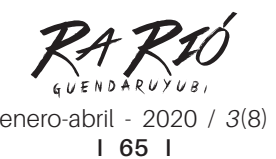

en caso de que los síntomas se presenten (He, Zhang \& Yang, 2013). Dado que la histamina también cumple otras funciones básicas y vitales en nuestro organismo, como intervenir en la producción de los jugos gástricos y formar parte del ciclo del sueño-vigilia, no siempre es "mala". ${ }^{3}$

Inmunodeficiencias (los soldados están débiles o han muerto...)

En temas anteriores se ha planteado cómo los mecanismos del sistema inmune controlan la invasión de agentes protegiéndonos de infecciones, toxinas o células cancerígenas. Ahora bien, ¿te has preguntado el efecto que tendría si alguno de sus mecanismos no fuera óptimo?

Cuando uno o varios componentes del sistema inmunitario no se desarrollan adecuadamente, sus funciones se ven comprometidas y se presentan trastornos denominados "inmunodeficiencias". Estas enfermedades pueden ser heredadas (congénitas) o adquiridas después del nacimiento. Si son heredadas, los niños pueden lucir saludables en un principio; sin embargo, cualquier infección que sería leve para otra persona, como una gripe o una infección en las encías, para ellos podrían ser mortales.

\section{El caso del niño burbuja}

David Vetter fue un niño originario de Texas, Estados Unidos, quien al nacer con una enfermedad desconocida en ese tiempo, los médicos lo condicionaron a vivir aislado del contacto humano. Sólo podía sobrevivir en el medio ambiente creado dentro de una cámara de plástico hermético en forma de burbuja, que le otorgaba un entorno libre de gérmenes (Figura 4). El "niño burbuja", como fue conocido David, sufría de una enfermedad llamada inmunodeficiencia combinada severa (SCID, por sus siglas en inglés), producida por deficiencias en el desarrollo normal de LT y las células NK (natural killers) (Berg, 2008; National Institute of Allergy and Infectious Disease, 2019).

${ }^{3}$ Se recomienda visitar el siguiente enlace para visualizar el papel de la histamina en las alergias: https://www.youtube.com/watch?v=gTdTOW8MZhE 


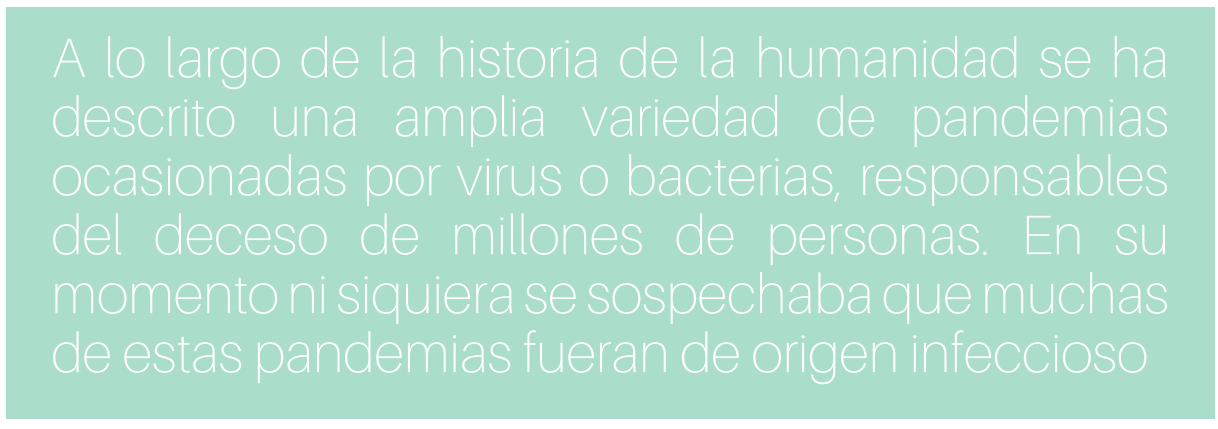

Por otra parte, hay otros tipos de inmunodeficiencias denominadas "secundarias", ya que pueden surgir en personas sanas y adquirirlas durante el curso de la vida a causa de un factor externo. Los casos menos severos son producidos por una mala alimentación, por estrés crónico o por no dormir lo suficiente. Estas inmunodeficiencias se recuperan teniendo una buena alimentación, descansando y durmiendo adecuadamente. Sin embargo, existen casos como el Síndrome de la Inmunodeficiencia Adquirida (SIDA), causado por el virus del VIH, que infecta a los LT, ocasionando su destrucción y afectando la respuesta inmune adaptativa de las personas que lo padecen, predisponiéndola a sufrir infecciones graves por microorganismos oportunistas que pueden provocarle la muerte (Dieffenbach \& Fauci, 2011).

\section{Vacunas: engañando al sistema inmunitario para que produzca memoria}

A lo largo de la historia de la humanidad se ha descrito una amplia variedad de pandemias* ocasionadas por virus o bacterias, responsables del deceso de millones de personas. En su momento ni siquiera se sospechaba que muchas de estas pandemias fueran de origen infeccioso, tal es el caso de la viruela (Variola virus), enfermedad que produce fiebre y ampollas, responsable de la muerte de mucha gente; pero algunas sobrevivían y al pasar de los días las ampollas se secaban, generando costras. Esta observación motivó que se empezaran a buscar métodos para combatirla; una técnica que se usó por muchos años fue la variolación (del latín varus, "marca en la piel"), que consistía en inocularse el polvo de la costra de las llagas en las fosas nasales. Este fue el primer método de inmunización. Fue hasta 1796 cuando Edward Jenner, en Gran Bretaña, inoculó en un niño materia de una lesión fresca de viruela de las manos de una lechera que estaba contagiada de viruela de vacas (menos letal que la de humano), posteriormente volvió a inocular al mismo niño, pero ahora con materia de una lesión de viruela humana y observó que el pequeño no adquirió la enfermedad. Con esto se descubrió un nuevo proceso de inmunización: la "vacuna" (del latín vacc) y la cura para la viruela. Años después, Louis Pasteur fue el primero en crear vacunas procesadas en su laboratorio, como la que combate la rabia. 


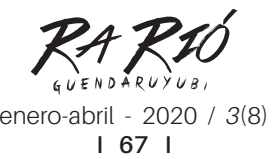

La primera dosis de esta vacuna en humanos la aplicó a un niño mordido por un perro rabioso, en 1885, teniendo éxito al lograr su supervivencia. Gracias a la vacunación sistemática, en la actualidad estas enfermedades se consideran erradicadas en humanos en todo el mundo (Hajj et al., 2015).

Las vacunas son compuestos que generan inmunidad tanto innata como adaptativa contra una enfermedad específica (Weinberger, Herndler, Schwanninger, Weiskopf \& Grubeck, 2008). Padecimientos que siguen presentes hoy en día, pero que se han prevenido con la vacunación son difteria, tétanos, tosferina, tuberculosis, influenza, hepatitis B, virus del papiloma humano, poliomielitis, paperas, rubeola y sarampión (Shukla \& Shah, 2018). Se han reportado brotes de sarampión en años recientes asociados a personas que carecen de su esquema de vacunación (Figura 5) (Smith, 2015; Jacobson, St. Sauver \& Finney, 2015). Existen varios tipos de vacunas:

a) Vacunas de virus atenuados: el virus se somete a sucesiones de cultivos celulares para debilitarlo y evitar su replicación en células humanas, pero que aún pueda ser reconocible por el sistema inmunitario para desencadenar la respuesta inmune y producir memoria inmunológica. Ejemplos de este tipo son las vacunas contra sarampión, rubeola, paperas y varicela.

b) Vacunas de microorganismos inactivados: el microorganismo se somete a condiciones de calor, radiación o a algunos químicos. El microbio ya no causa enfermedad, pero igual será reconocido y generará memoria. Ejemplos de estas vacunas son contra poliomielitis y hepatitis $A$.

c) Vacunas de subunidad: contienen sólo porciones del microorganismo que puede presentarse como antígeno, activar al sistema inmunitario e inducir memoria; por ejemplo, la vacuna contra hepatitis B e influenza.

d) Vacunas conjugadas: están diseñadas a partir de fracciones del recubrimiento bacteriano combinadas con una proteína transportadora, para generar mejores respuestas. Las vacunas en contra de toxinas se preparan inactivando o debilitando su toxicidad, 
usando calor o químicos, y acoplándolas a moléculas que incrementan su capacidad de activar al sistema inmune e inducir memoria. Por ejemplo, la vacuna contra el tétanos.

Actualmente los científicos trabajan en nuevas tecnologías de vacunas basadas en vectores virales* y ácidos nucleicos (ADN y ARNm), los estudios clínicos han demostrado que estas vacunas ofrecen un gran potencial para inducir respuestas protectoras en humanos; no obstante, aún siguen en estudio y pruebas (Shukla \& Shah, 2018; Hajj et al., 2015; Rauch, Jasny, Schmidt \& Petsch, 2018).

En general, cuando los antígenos de un microorganismo se inyectan en forma de vacuna, son acoplados con adyuvantes* como sales de aluminio, que incrementan la estimulación del sistema inmunitario. En el sitio de aplicación se activa la respuesta inmune innata, induciendo la producción de citocinas proinflamatorias por los macrófagos, los cuales proveen más señales de daño que favorecen la activación de las células dendríticas y migran a ganglios linfáticos, donde activan a la respuesta inmune adaptativa para la producción de LT y LB de memoria, células plasmáticas de vida larga y la generación de anticuerpos de tipo IgG de alta afinidad (Figura 6). Todo esto en conjunto aporta protección a largo plazo a la persona, sin necesidad de haber padecido la infección (Weinberger et al., 2008). ${ }^{4}$

En México, el esquema de vacunación que se debe cumplir y que suministra la Secretaría de Salud es que se describe en la Figura 7. La aplicación de las vacunas deben llevarla a cabo profesionales de la salud y el médico debe explicar las ventajas, los componentes de la vacuna, la administración, las contraindicaciones y los efectos adversos que pueda manifestar el paciente al que le sean administradas, que generalmente son niños.

${ }^{4}$ En el siguiente enlace se puede visualizar cómo funcionan las vacunas: https://www.youtube. $\mathrm{com} /$ watch?v=rb7TVW77ZCs\&list=LLZggffdpjhzgDrs10sOnv0A\&index=6 

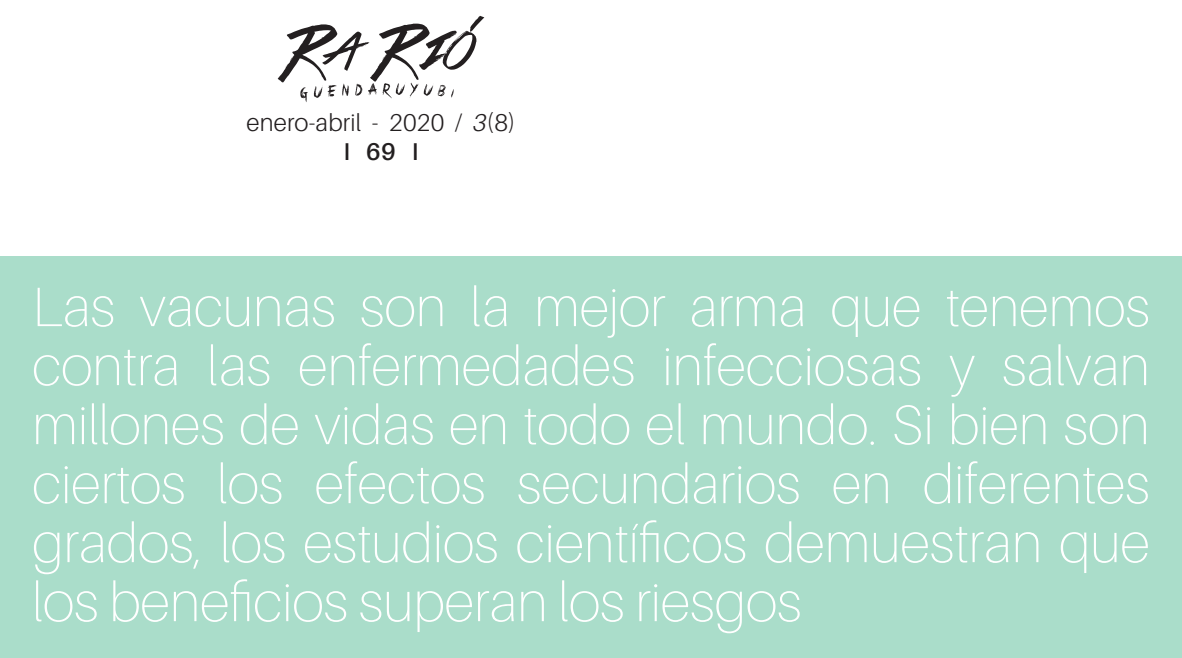

Hasta ahora la vacunación ha salvado muchas vidas y fue uno de los avances más grandes de la ciencia. En 1996 se publicó la iniciativa para el desarrollo de la vacuna contra una de las pandemias de la actualidad: el VIH, pero todavía no se ha logrado producir y los científicos siguen ocupados en ello.

Pero, ¿ipor qué a pesar de los beneficios de las vacunas algunas personas optan por no usarlas!?

Las vacunas están diseñadas para proteger contra las enfermedades, pero como cualquier otro medicamento, pueden ocasionar algunos efectos secundarios (en su mayoría leves), como malestar, hinchazón o enrojecimiento en el sitio de inyección, en situaciones poco comunes. En un reducido número de personas pueden provocar reacciones alérgicas o convulsiones que ponen la vida en riesgo. Por otra parte, la idea de que surjan discapacidades después de aplicarse una vacuna hizo que por diferentes motivos (sanitarios, religiosos, políticos, o filosóficos) algunos pensaran que las vacunas, y en definitiva el acto de vacunarse, pone en peligro la salud en lugar de protegerla. Ante esto, nuevamente enfermedades que estaban casi desarraigadas, como el sarampión, han resurgido (Unicef, 2019; OMS, 2018). Si bien son ciertos los efectos secundarios en diferentes grados, los estudios científicos demuestran que los beneficios superan los riesgos. Por lo tanto, las vacunas son la mejor arma que tenemos contra las enfermedades infecciosas y salvan millones de vidas en todo el mundo. 


\section{Glosario}

Adyuvantes: Sustancia que se añade a una vacuna para potenciar la respuesta inmunitaria frente a un antígeno.

Anérgicos: Son los linfocitos que se encuentran en un estado de inactividad; es decir, son incapaces de responder ante el encuentro con su antígeno correspondiente.

Inmunosuprimido: Individuo con falla o falta en algunos de los mecanismos del sistema inmune, que impide la respuesta eficaz.

Pandemia: Enfermedad infecciosa que se extiende por un gran territorio, inclusive por todo el mundo.

Simbiosis: Cooperación entre dos organismos para beneficiarse y favorecer mutuamente su desarrollo funcional.

Vectores virales: Virus modificados, utilizados para transferir información genética a las células.

\section{Referencias}

Abbas, A. K., Lichtman, A. H., \& Pillai, S. (2018). Inmunología celulary molecular. Barcelona: Saunders-Elsevier.

Aluvihare, V. R., Kallilourdis, M., \& Betz, A. G. (2004). Tolerance, suppression and the fetal allograft. Journal of Molecular Medicine, 83(2), 88-96. doi:10.1007/s00109-004-0608-2

Berg, L. J. (2008). The "Bubble Boy" Paradox: An Answer That Led to a Question. The Journal or Immunology, 181(9), 5815-5816. doi: 10.4049/jimmunol.181.9.5815

Bluestone, J. A. (2011). Mechanisms of Tolerance. Immunological Reviews, 241, 5-19. doi: 10.1111/j.1600-065X.2011.01019.x

Bosch, X. (2011). Systemic Lupus Erythematosus and the Neutrophil. New England Journal of Medicine, 365(8), 758-760. doi: 10.1056/NEJMcibr1107085

Calzada, D., Baos, S., Cremades-Jimeno, L., \& Cárdaba, B. (2018). Immunological Mechanisms in Allergic Diseases and Allergen Tolerance: The Role of Treg Cells. Journal of Immunology Research, 1-10. doi: 10.1155/2018/6012053

Dieffenbach, C. W., \& Fauci, A. S. (2011). Thirty years of HIV and AIDS: Future challenges and opportunities. Annual International of Medicine, 154(11), 766-771. doi: 10.7326/00034819-154-11-201106070-00345

Doherty, M., \& Robertson, M. (2004). Some early. Trends in Immunology, 25(12), 623-631. doi:10.1016/j.it.2004.10.008.

Ermann, J., \& Fathman, C. G. (2001). Autoimmune diseases: genes, bugs and failed regulation. Nature Immunology, 2(9), 759-761. doi: 10.1038 / ni0901-759

Hajj Hussein, I., Chams, N., Chams, S., El Sayegh, S., Badran, R., Raad, M., Gerges-Geagea, A., Leone, A., \& Jurjus, A. (2015). Vaccines Through Centuries: Major Cornerstone of global Health. Frontiers in Public Health, 3, 269. doi:10.3389/fpubh.2015.00269.

He, S-H., Zhang, H-Y., \& Yang, P-C. (2013). Mast Cells and Basophils are Essential for Allergies: Mechanisms of Allergic Inflammation and a Proposed Procedure for Diagnosis. Acta Pharmacologica Sinica, 34(10), 1270-1283. doi: 10.1038/aps.2013.88. 
Jacobson, R. M., St. Sauver, J. L., \& Finney Rutten, L. J. (2015). Vaccine Hesitancy. Clinic Proceedings, 90(11), 1562-1568. doi:10.1016/j.mayocp.2015.09.006

Jadue, N., \& González, I. (2012). Inmunopatogenias de las enfermedades autoinmunes. Revista Médica clínica Las Condes, 23(4), 464-472. doi: 10.1016/S0716-8640(12)70337-1

Murphy, K., Travers, P., \& Walport, M. (2009). Inmunología de Janeway. México: McGrawHill.

Organización Mundial de la Salud (OMS). (2018). Recuperado de: https://www.who.int/es/newsroom/detail/29-11-2018-measles-cases-spike-globally-due-to-gaps-in-vaccination-coverage

Rauch, S., Jasny, E., Schmidt, K. E., \& Petsch, B. (2018). New Vaccines Technologies to Combat Outbreak Situations. Frontiers in Immunology, 9. doi:10.3389/fimmu.2018.01963

Scheurer, S., Toda, M., \& Vieths, S. (2015). What makes an allergen? Clinical \& Experimental Allergy. doi: 10.1111/cea.12571

Schwartz, R. H. (2012). Historical Overview of Immunological Tolerance. Cold Spring Harbor Perspectives in Biology, 4(4). doi: 10.1101/cshperspect.a006908

Shukla, V. V., \& Shah, R. C. (2018). Vaccinations in Primary Care. The Indian Journal of Pediatrics, 85(12), 118-1127. doi:10.1007/s12098-017-2555-2.

Smith, M. (2015). Vaccines Safety: Medical Contraindications, Myths, and Risk Communication. Pediatrics in Review, 36(6), 227-238. doi:10.1542/pir.36-6-227.

United Nations Children's Fund (UNICEF]. (2019). La alarmante oleada mundial de casos de sarampión es una amenaza creciente para la infancia. Nueva York. Recuperado de https://www. unicef.org/es/comunicados-

prensa/alarmante-oleada-mundial-sarampion-amenaza-creciente-para-infanciaWeinberger,

B., Herndler-Brandstetter, D., Schwanninger, A., Weiskopf, D., \& Grubeck-Loebenstein, B. (2008). Biology of Immune Resposes to Vaccines in Elderly Persons. Clinical Infectious Diseases, 46(7), 1078-1084. doi:10.1086/529197.

Zhao, Q., \& Elson, C. O. (2018). Adaptive Immune Education by Gut Microbiota Antigens. Immunology, 154(1), 28-37. doi: 10.1111/imm.12896. 
Figura 1. Tolerancia central y periférica frente a antígenos propios

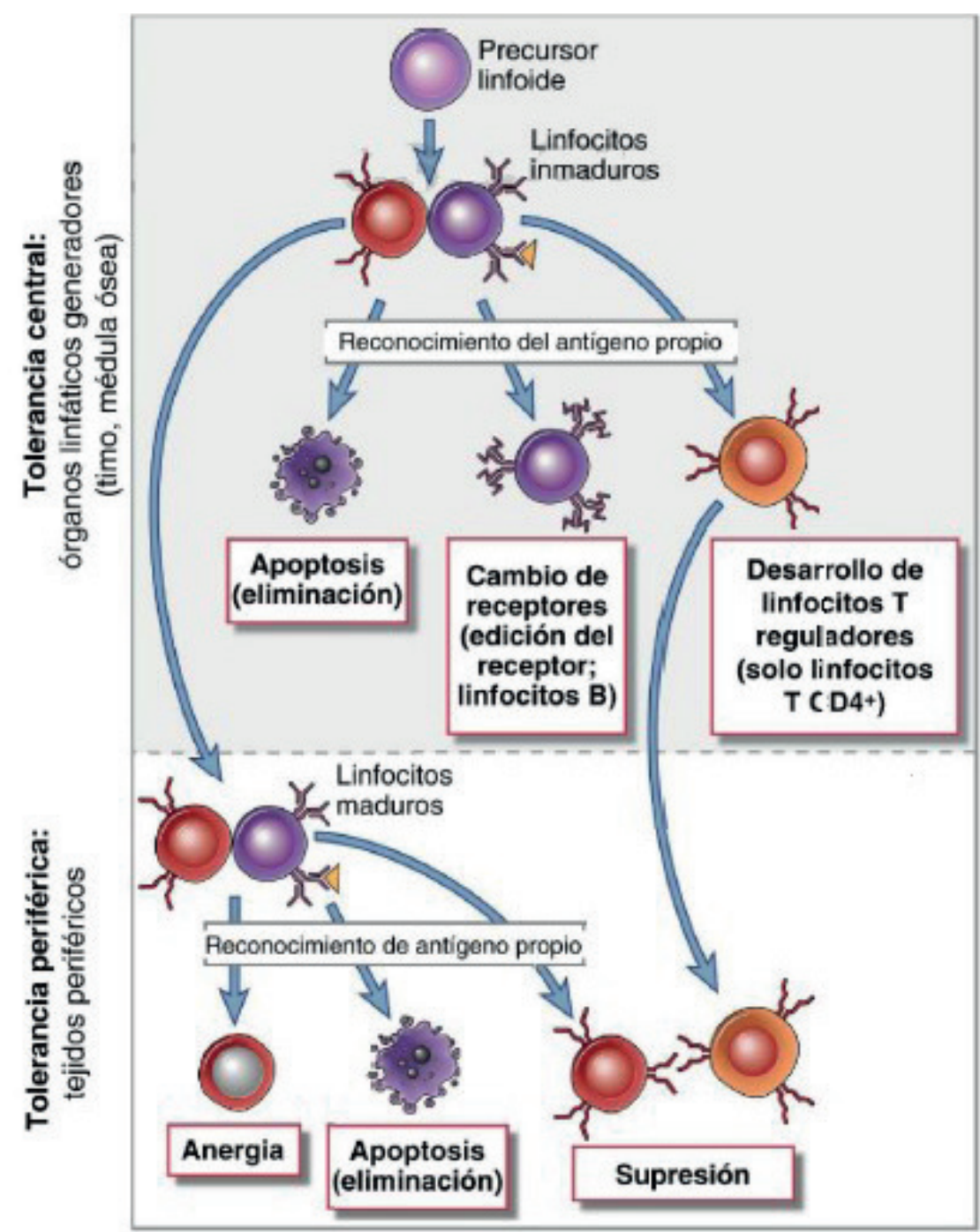

En la tolerancia central que se lleva a cabo en los órganos linfoides primarios (timo y médula ósea), los linfocitos inmaduros que reconocen antígenos propios son eliminados. Sin embargo, aquí también estos linfocitos pueden tener la oportunidad de cambiar su receptor a uno que no reconozca antígenos propios (sólo en linfocitos B) o evolucionar a linfocitos T reguladores (sólo linfocitos $T$ CD4+). Por otro lado, algunos linfocitos que reconocen antígenos propios pueden salir a sangre periférica y viajar por todo el organismo, donde al encontrarse con un autoantígeno son inactivados (anergia), eliminados o suprimidos por los linfocitos T reguladores, a lo que se conoce como tolerancia periférica (Abbas, Lichtman \& Pillai, 2018). 


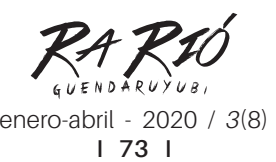

Figura 2. Factores que provocan el desarrollo de enfermedades autoinmunes

La predisposición genética es el primer factor para desarrollar una enfermedad autoinmune. En segundo lugar, algún un factor ambiental, como una infección, un agente tóxico o un medicamento, puede desencadenar una respuesta inflamatoria crónica con la posibilidad de activar algunas células autorreactivas de baja afinidad y la consecuente destrucción de uno o más órganos propios. Fuente: Imagen tomada

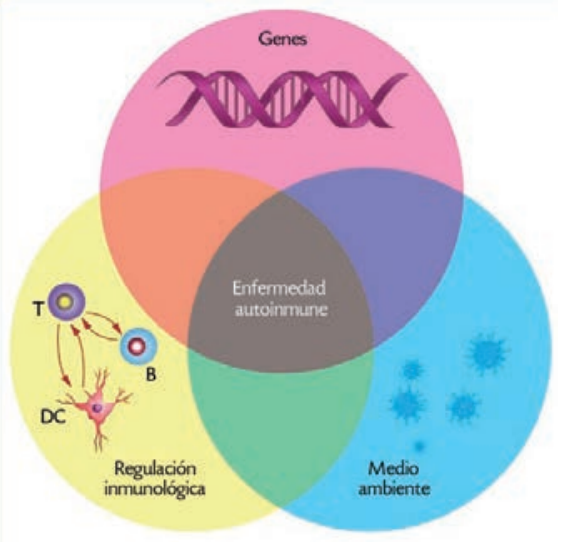
y modificada de Ermann \& Fathman, 2001.

Figura 3. Etapas de una reacción alérgica

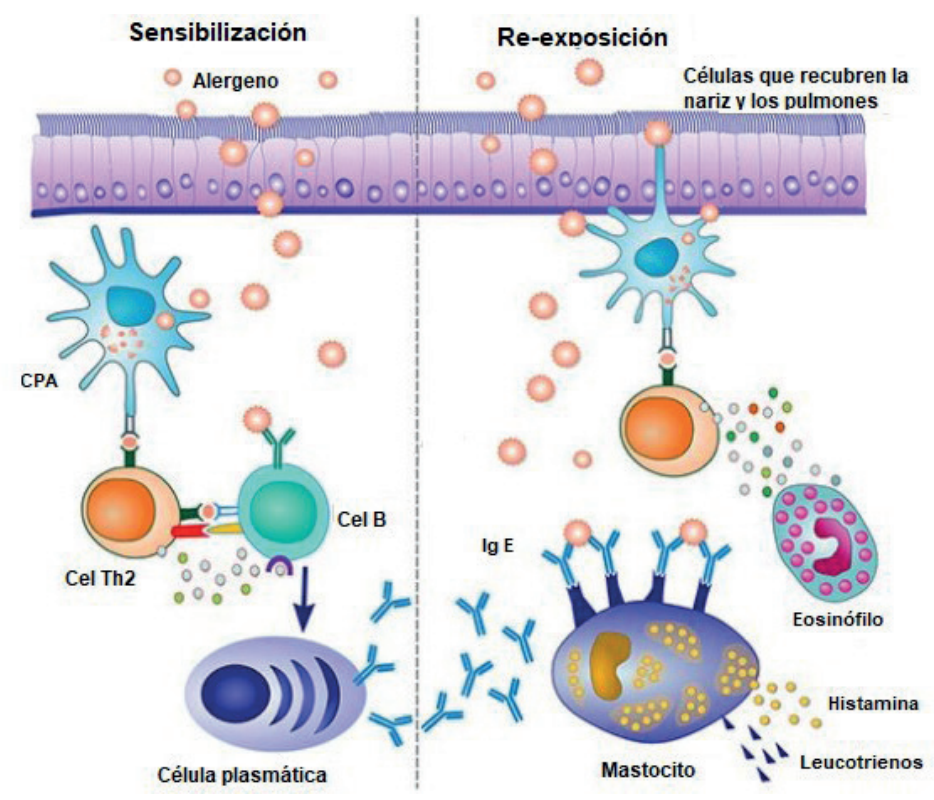

Un primer encuentro del alérgeno (por ejemplo, polen) con personas alérgicas desencadena la producción de $\lg \mathrm{E}$ por los linfocitos $\mathrm{B}$, inducidos por linfocitos Th2. La IgE tiene la propiedad de unirse fuertemente a la membrana plasmática de los mastocitos y basófilos (etapa de sensibilización). En un segundo encuentro (cuando la persona inhala polen) las células presentadoras de antígeno (CPA), situadas en el revestimiento de la nariz y pulmones, engullen al alérgeno y lo procesan, acoplándolo en las regiones hipervariables de la IgE que ya está unida en la superficie de los mastocitos y basófilos, generando la desgranulación de dichas células ricas en histamina y otras sustancias que inducen inflamación. Fuente: Imagen tomada y modificada de https://www.pinterest.com.mx/ pin/493918284114931267/?lp=true 


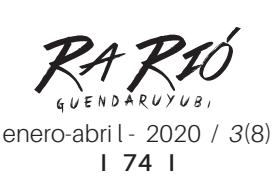

Figura 4. Fotografía de David, el "niño burbuja"

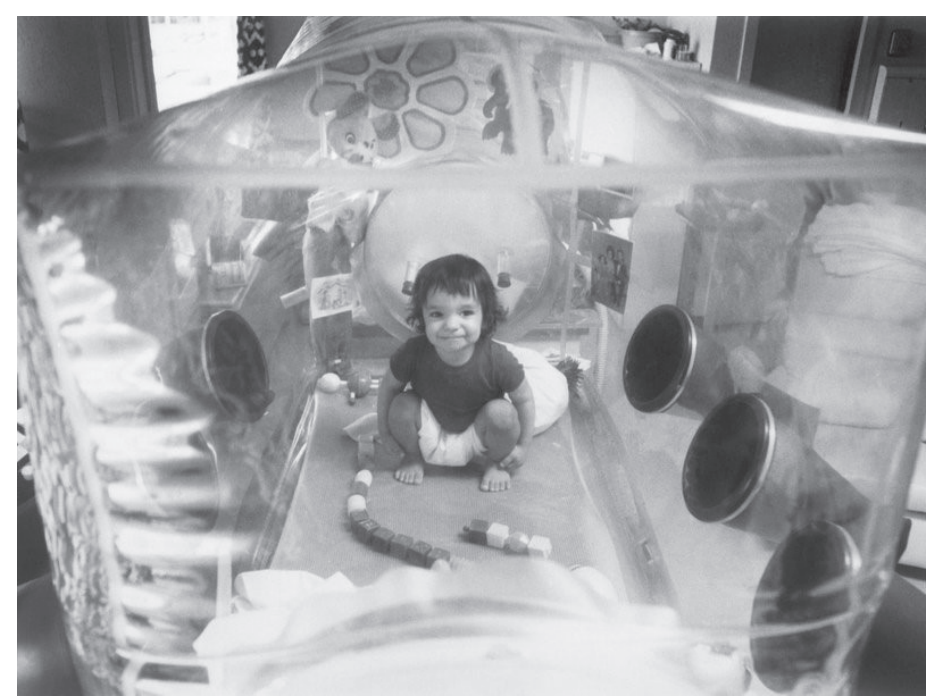

David jugando dentro de su burbuja de plástico que lo protegía del ambiente y lo mantenía con vida. Fuente: Tomado de Bettmann/Bettmann archive, https://www. wbur.org/npr/657080482/opinion-the-doctor-and-the-boy-in-the-bubble

Figura 5. Niño con muestra clínica de sarampión

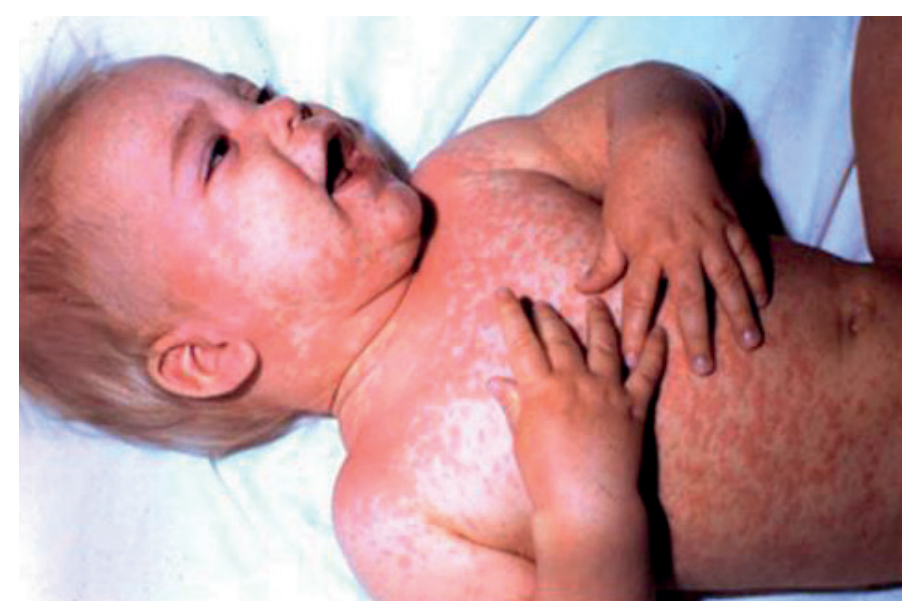

El sarampión es un problema de salud prevenible con la vacunación. Fuente: Smith, 2015. 
Figura 6. Esquema representativo de la respuesta inmune desencadenada tras la aplicación de una vacuna

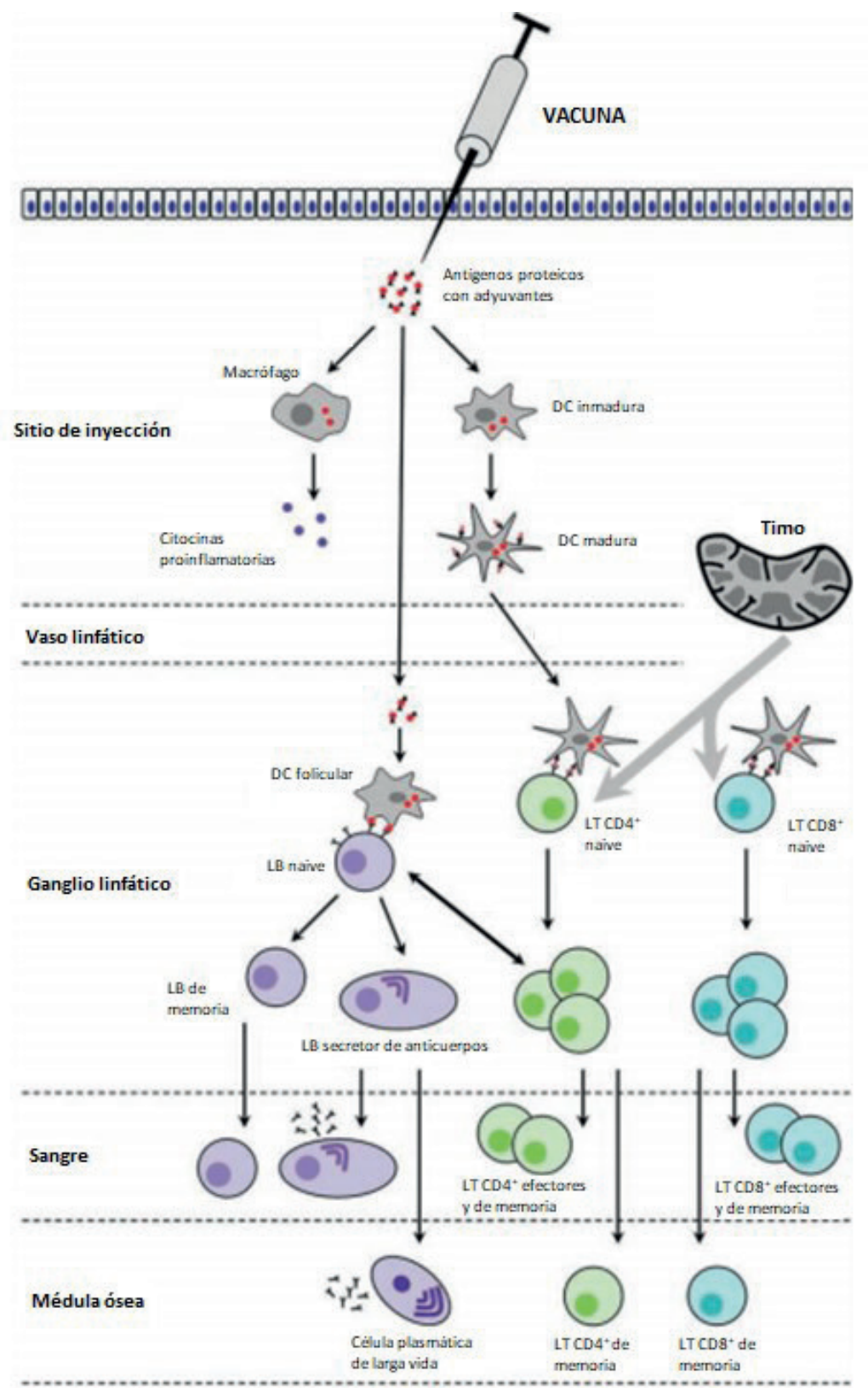

Las células dendriticas (DC) capturan y procesan los antígenos presentes en las vacunas, los presentan a los linfocitos T (LT). Los linfocitos B (LB) también reconocen a los antígenos y se diferencian a células plasmáticas para producir anticuerpos. Este efecto hace que se generen tanto LT como LB de memoria. Fuente: Imagen modificada de Weinberger et al., 2008. 
Figura 7. Esquema Nacional de Vacunación de los Estados Unidos Mexicanos

\begin{tabular}{|c|c|c|c|c|}
\hline \multicolumn{5}{|c|}{ Esquema Nacional de Vacunación } \\
\hline Nacimiento & BCG & \multicolumn{3}{|c|}{ Hepatitis B } \\
\hline $\begin{array}{c}2 \\
\text { meses }\end{array}$ & $\begin{array}{l}\text { Pentavalente } \\
\text { acelular }\end{array}$ & $\begin{array}{l}\text { Hepatitis } \\
\text { B }\end{array}$ & Rotavirus & $\begin{array}{l}\text { Neumococo } \\
\text { conjugada }\end{array}$ \\
\hline $\begin{array}{c}4 \\
\text { meses }\end{array}$ & \multicolumn{2}{|c|}{ Pentavalente acelular } & Rotavirus & $\begin{array}{c}\text { Neumococo } \\
\text { conjugada }\end{array}$ \\
\hline $\begin{array}{c}6 \\
\text { meses }\end{array}$ & $\begin{array}{l}\text { Pentavalente } \\
\text { acelular }\end{array}$ & $\begin{array}{l}\text { Hepatitis } \\
\text { B }\end{array}$ & Rotavirus & Influenza \\
\hline $\begin{array}{c}7 \\
\text { meses }\end{array}$ & \multicolumn{4}{|c|}{ Influenza segunda dosis } \\
\hline $\begin{array}{c}12 \\
\text { meses }\end{array}$ & \multicolumn{3}{|c|}{ SRP } & $\begin{array}{l}\text { Neumococo } \\
\text { conjugada }\end{array}$ \\
\hline $\begin{array}{c}18 \\
\text { meses }\end{array}$ & \multicolumn{4}{|c|}{ Pentavalente acelular } \\
\hline $\begin{array}{c}24 \\
\text { meses } \\
\text { (2 años) }\end{array}$ & \multicolumn{4}{|c|}{ Influenza refuerzo anual } \\
\hline $\begin{array}{c}36 \\
\text { meses } \\
\text { (3 años) }\end{array}$ & \multicolumn{4}{|c|}{ Influenza refuerzo anual } \\
\hline $\begin{array}{c}48 \\
\text { meses } \\
\text { (4 años) }\end{array}$ & \multicolumn{3}{|c|}{ DPT (refuerzo) } & $\begin{array}{l}\text { Influenza } \\
\text { refuerzo } \\
\text { anual }\end{array}$ \\
\hline 59 & \multicolumn{4}{|c|}{ Refuerzo anual Influenza (octubre-enero) } \\
\hline (5 años) & \multicolumn{4}{|c|}{$\begin{array}{l}\text { OPV (polio oral) de los } 6 \text { a los } 59 \text { meses en } 1^{a} \text { y } 2^{a} \\
\text { Semanas Nacionales de Salud }\end{array}$} \\
\hline $\begin{array}{c}72 \\
\text { meses } \\
\text { (6 años) }\end{array}$ & \multicolumn{4}{|c|}{ SRP (refuerzo) } \\
\hline $\begin{array}{c}11 \text { años o } \\
\text { quinto grado } \\
\text { de primaria }\end{array}$ & \multicolumn{4}{|c|}{ VPH (Virus de Papiloma Humano) } \\
\hline
\end{tabular}

BCG: Bacillus Calmatte-Guérin. Pentavalente acelular es una vacuna combinada y protege contra difteria, tétanos, tosferina, poliomielitis y haemophilus influenza tipo B. Fuente: Recuperado de https://www.gob.mx/salud/articulos/esquema-devacunacion. 